\title{
When Games and Gambling Collide: Modern Examples and Controversies
}

\begin{abstract}
The intersection of gaming and gambling has a long lineage. In recent years this process has amplified, arguably accelerated by developing technological infrastructures which facilitate rapid payment purchases and online and real-time systems which allow companies to communicate directly with users and users to communicate with each other. This chapter traces key issues relating to some notable recent examples of the gaming/gambling intersection. It includes controversies about the status of social casino games and loot boxes; the development and expansion of daily fantasy sports markets; the betting and wagering of skins won or bought through digital games, and; rising opportunities to bet on esports. Each exemplifies how these activities are products of a unique set of social and economic circumstances, how corporations are diversifying and becoming part of a more complex gaming/gambling ecosystem and using data to drive growth, all of which raise particular issues for consumer protection.
\end{abstract}

Keywords Gambling · Gaming · Skin betting · Loot boxes · Daily fantasy sports $\cdot$ Esports $\cdot$ Social casino · Corporations

H. Wardle, Games Without Frontiers?, Leisure Studies in a Global Era, https://doi.org/10.1007/978-3-030-74910-1_3 
As we saw in the previous chapter, games and gambling have always been related, whether that's through people wagering on certain games, games being used to warn against the vice of gambling or games taking inspiration from broader cultural reference points-like premier horse races or the online poker boom. From the turn of the twenty first century though, these processes have amplified. Both gaming and gambling industries capitalised upon advances in technology to generate new products, which in turn gave rise to concerns about the growing intersection of games and gambling. This chapter traces the processes that underpin this acceleration by examining five key topics: social casino, daily fantasy sports, esports, skin betting and loot boxes. They are far from the only examples that could have been chosen, but are the ones that best exemplify some of the processes at work.

\section{Social Casino}

Before loot boxes became the poster child for the integration of gaming and gambling, there were social casinos. Back in 2012, when loot boxes were quietly starting to be introduced within digital games, academic, policy and regulatory attention was almost entirely focused on social casinos. Social casino is a catch all term describing a range of games which replicate the look and feel of casino games and slots but are played for virtual currency. One of the first academic debates centred on what they should be called-different terms were mooted though the term "social" was always a prefix. Calling them social is somewhat of a misnomer, there's not much about these games that are especially social. Yes, they contain features which aim to replicate the look and feel of other online gaming communities, with leader boards and functions where you can share your experiences with your network, but the term "social" mainly pertains to the social media platforms in which they were originally embedded, namely Facebook.

Social casino came to prominence with games like Zynga's Texas Hold 'em Poker launching in 2007, followed by titles like DoubleDown Casino launching on Facebook in 2010, who grew quickly to amass over 4 million monthly users. This created a large target audience on the Facebook platform for advertisers but also meant that companies like Zynga or DoubleDown were generating masses of data on people who used their products. DoubleDown Casino was quickly followed by other brands, like Slotomania, who also attracted a large, and worldwide, base of users. 
To some, the popularity of these games was mind boggling-that people would wager virtual currency on roulette or slots games for the chance of winning more virtual currency, and do this repeatedly, seemed curious. And debate quickly erupted about the classification and impact of these games. The initial debate centred on whether these games met legal and technical definitions of gambling. In Britain, as elsewhere, the industry regulator said not, because the currency wagered was virtual (Gambling Commission, 2016). On these games, you get given a certain amount of virtual currency at sign up, can win virtual currency through other bonus mechanisms or can buy additional virtual currency to play with. If you win, you win more of the in-game currency. The British regulator (the Gambling Commission) formed the opinion that this did not represent a "money's worth" prize and therefore deemed that these games did not meet Britain's current legal definition of gambling. However, the Gambling Commission's Chairman, Philip Graf, conceded that this was an untested point of law (Graf, 2013). In the USA, it did not take long for this legal point to be tested.

In the early 2000s, Washington State (USA) undertook an active policy to encourage big gaming companies to locate their businesses there. They offered preferential tax rates and had the geographic fortune to find themselves situated equidistant between Asian and European markets. Unsurprisingly, the companies followed. Social casino companies also located themselves in Seattle. Notably DoubleDown casino (trading as DoubleDown Interactive) continues to have its headquarters on Seattle's 5th Avenue.

Just a few years after their inception, Washington State's attention to the collision of gambling and gaming was amplified when in 2015 Cheryl Kater bought a lawsuit against Big Fish Casino, or rather Churchill Downs, their parent company. Big Fish Casino was a social casino brand, offering poker, blackjack and slots played for virtual cash. Like so many other social casino brands, Big Fish embraced smart phone technology and developed standalone apps for their games, which were free to download. Which is exactly what Cheryl Kater had done in 2013. As with so many of these games, once your initial allocation of currency ran out, the main way to continue playing was to buy more, though you could earn currency in other ways too-like logging into the app on a daily basis. Within a relatively short period of time Cheryl found herself buying new currency and racking up initial debts of over \$1000. Faced with such expenditure, Cheryl launched a lawsuit arguing that Big Fish Casino 
violated Washington State's gambling laws (Washington State Gambling Commission, 2018). It was a bold move.

Washington State notoriously has some of the broadest definitions of what constitutes gambling and the case hinged around whether virtual currency, the casino chips purchased, represented a "thing of value". Ms Kater initially wanted to be able to recover the $\$ 1000$ she lost under Washington Statute which allowed people to recover money or anything of value lost from an illegal gambling game. The first case was thrown out by the courts. Undeterred, Ms Kater appealed and in 2018, the Ninth Circuit for the US Court of Appeals agreed with her. Big Fish casino chips were deemed a "thing of value", namely because you had to own them to play the game, and only through possessing these virtual chips could you be afforded the privilege of playing. The judges stated that this process gave these virtual casino chips inherent value, and thus having been designated a "thing of value", games played with them constituted gambling under Washington State law (US Court of Appeals, 2018). Ms Kater's case also included details of the secondary marketplaces where these casino chips could be bought and sold, though bizarrely, the Court of Appeal did not endorse this aspect of her argument. The Court of Appeal held that as such sales were expressly forbidden in Big Fish Casino's terms and conditions this was irrelevant to the arguments of the value of these chips (US Court of Appeal, 2018). This overlooks that, like it or not, many people do use these secondary marketplaces to trade virtual currency, putting a real money value on a digital object. It was the equivalent of saying that because the marketplace for drugs is illegal, the trades which occur there have no bearing on whether the drugs have value or not. Nonetheless, this ruling paved the way for a class action lawsuit to be brought against Churchill Downs and Aristocrat (who bought Big Fish Casino in 2018). After years of legal wrangling, the class action lawsuit was settled in principle in May 2020, with a reported \$155 million pay-out agreed to Kater and her co-plaintiffs.

This case is especially interesting, because the decision rested on the type of value that the virtual currency was felt to convey. As early as 2005 Edward Castrovona wrote that "once one recognised that a piece of silver [in the game] can have value, just like the US dollar, one must realise that a silver piece is not just merely like money - it is money" (Castronova, 2005: 47). If we accept that the virtual currency contained within these games holds a range of values both within the game play and to the player, then social casino products become more than just games, they become 
gambling simulations. As the Ninth Circuit Court of Appeal stated, part of this value is in purchasing access to a product; part of this value is also in the direct exchange of this currency for fiat currency; part of its value is also held within the symbolism that it provides within the game and for that game community-where leader boards list highest scores by the amount of virtual money won. It is worth remembering that the money in our pockets is just a symbol of something held to have common valueand that common value is accepted and underpinned by other things within our communities. In these games, the unit of exchange wagered is something that has a recognised and quantifiable value to the community of players. Yet it is particularly telling that, in Great Britain at least, current legal definitions do not deem this to be gambling (Gambling Commission, 2016). These definitions were written in the early 2000s and reflect the provision, scale and scope of products available at that time. Gaming cultures, and the different ways of financing and supporting them especially through transactions like the sale of digital currency, is something that was not foreseen by legislators and arguably highlights a pressing need to revisit our technical lexicon.

The debate about definitions arguably masks broader concerns-that of impact. The rapacious growth of social casino led people to question whether engaging in these "games" could lead to harm? Could it encourage people to transition to "for money" gambling? Could they change the views, attitudes and behaviours of a cohort of young people? Looking at Cheryl Kater's class action, the answer to some of these questions is yes-some of her plaintiffs reported extraordinary levels of debt as a result of engaging in social casino products. Other concerns were amplified for young people. As early as 2012, it was estimated that in Britain, $16 \%$ of boys and $6 \%$ of girls aged $11-16$ were playing social casino games in the past week, with $8 \%$ of boys and 3\% of girls playing poker via platforms like Facebook (Parke et al., 2012). Researchers cautiously estimated that around 300,000 young people in Britain regularly played these games, making them more popular than participating in music groups, faith groups or going to youth centres. Children who played these games were also much more likely to be engaging in other forms of gambling, be it betting among themselves or gambling on other, age restricted, activities. That said, there were a chunk of children who only played social casino games and didn't engage in other forms of gambling: $27 \%$ of boys and $42 \%$ of girls who played social casino games did this and this only (Parke et al., 2012). For those who may be wondering, 
social casino games do not have effective age-verification controls, so it is perfectly possible for them to be played by children, regardless of terms and conditions of social media platforms.

These data inevitably raised questions about gateway effects-would children playing these social casino games, with the look and feel of real gambling, transition to real money gambling? Of course, looking at behaviour over time requires the passage of time. It is now some ten years since these games emerged yet the evidence base around these questions remains nascent, at best. In 2015, a survey of American adults found there were migration effects, with over one in four social casino players starting to gamble online when interviewed six months later (Kim et al., 2015). Other studies have simply asked people to report their own perceptions of influence, with $19 \%$ saying they gambled with real money as a result of engagement in social casino games (Gainsbury et al., 2016). Yet, there has been very little examination of children's patterns of behaviour. The crude answer to this question is that we don't really know. Most studies conducted are drawn from small, non-generalisable samples and either look at the associations between social casino engagement and other gambling behaviours (my own work included) or ask participants to report how they felt playing social casinos impacted on subsequent "real money" gambling or desires to engage in real money gambling, all of which have limitations. A recent review has described the evidence as both limited and tentative (King, 2018). In short, we lack the body of evidence that tells us if young people transition into "for money" gambling, why, how and under what circumstances. We are now nearly ten years on from the heyday of interest in social casinos and seem no closer to being able to answer critical questions about this potential pathway.

Why is this? In Britain, there was an initial flurry of interest from the regulator, who declared a "watching brief" of the situation, followed by statements that social casinos do not meet their definition of gambling but do raise questions about their role in the further normalisation of gambling, among other things (Gambling Commission, 2016; Parke et al., 2012). But Britain has a very different gambling landscape to most other jurisdictions, especially North America. In Britain, if as a person aged 18 and over you want to gamble on slots, on casino games, on poker, you can-you can do this on any high street (given the preponderance of fruit machines and the then ubiquitous Fixed Odd Betting Terminals, which offer roulette games). You can also do this online and via apps on your mobile phone. Reflecting back on this time, there was 
a palpable sense that if adults chose to play social casino games, it was because they really wanted to play that product-not because it was a proxy for gambling not otherwise available to them. This, arguably, had the effect of essentially diminishing policy interest in this area, though in 2020 the incumbent Chief Executive of the Gambling Commission attempted to revive some interest in this issue (House of Lords, 2020a).

In retrospect, the perhaps the questions being asked were wrong. They were entirely focused on social casino as a pathway to real money gambling and mainly focused on children. But as we've seen, this is not the only potential impact. People can become over-involved with these types of games and spend too money and time engaging with them. Perhaps the questions we should have been asking were not whether these products approximate gambling, but rather what are their capacity for harms, in all its forms? My colleague, David Zendle (2020), estimates that around $3-4 \%$ of British adults continue to play social casino games. Their level of expenditure is unknown, but that could represent 1.5 million British adults playing these games (though Dr Zendle himself would urge us to exercise caution in doing such extrapolations). ${ }^{l}$ This, it would appear, remains a considerable activity and one about which we know very little.

In Britain, children are singled out for special regulatory protection under the British 2005 Gambling Act. Yet still, the regulator and central government policymakers did not deem these concerns sufficient to warrant specific investigation of them. Aside from an initial scoping review (Parke et al., 2012), there has been little British-based investigation of social casino gaming among children and young people. This seems strange, given that in Britain, as elsewhere, social casino games, like Texas Hold 'em Poker or Bingo Blitz rank as some of the highest grossing in money terms. Looking at these rankings shows the enduring nature of these games and their ongoing ability to generate money. At the time of writing, in the USA, Slotomania ranked 26th and DoubleDown casino ranked 38th in the highest grossing IOS apps. In Canada, Slotomania was 18th, followed by BingoBlitz in 33rd and Jackpot Party in 34th. In Australia, which allows online sports betting but not online casino gambling, the app taking the number one spot for highest gross income was Lighting Link Slots Casino, a social casino game developed

\footnotetext{
${ }^{1}$ His study is based on a survey which used non-probability sampling methods and so should not, typically be used to generalise to the broader population.
} 
and owned by Aristocrat. This is the same firm which bought Big Fish Casino in 2018 and which develops and runs many of Australia's slot machines and casinos. This was followed by Cashman casino slots in 6th (also owned by Aristocrat), Slotomania in 9th and another six social casino companies ranking in the top 50 . Social casino is clearly a major business in Australia. ${ }^{2}$

The examples from both Australia and the USA are telling. Lighting Link Slots Casino is the latest release from Aristocrat Gaming who are major gambling providers headquartered in Australia. Aristocrat started life in the 1950s designing and selling slot machines. Since then they have adapted and diversified their product range, still designing and selling slot games but also moving into casinos, software management and social casino. Aristocrat's first foray into social casino was in 2012 when it bought Product Madness, one of the top five rated social casino companies at the time (at the time of purchase, it reportedly had 500,000 daily active users) (Gambling Insider, 2012). They have taken an aggressive approach to social casino and expanded with other acquisitions, paying $\$ 990$ million for Big Fish Casino, taking this on despite the outstanding class action case against them, a portion of the settlement Aristocrat now have to pay. In 2019, Aristocrat's CEO Trevor Croker announced their intention to invest heavily in social casino, arguing that it is a vital component of long-term growth (Blaschke, 2019). He had no idea how prescient his words would turn out to be. With traditional forms of gambling (like bricks and mortar casinos) already struggling, the COVID19 pandemic demonstrated that the most resilient companies were those with diversified products and a strong digital presence. As the global pandemic took hold, Aristocrat's top three social casino titles reportedly surged up the Android App rankings in April 2020 (GGR Asia, 2020). It seems likely that the COVID-19 pandemic may result in renewed business interest in the social casino market.

Yet, the opportunity to diversify business portfolios is not the only opportunity social casino presents. It also provides opportunities to embed brand titles within a different genre. This is something at Aristocrat have done with gusto, especially with their Lightning Links Slots

\footnotetext{
2 The data cited in this section was generated through the website AppAnnie, looking at the highest grossing apps for each jurisdiction listed by AppAnnie on 7 August 2020. It's not clear how AppAnnie generates its estimates but the methods are likely to be consistent between countries.
} 
games. Lightning Links has become one of the most important slot games designed by Aristocrat, so important that it is currently embroiled in a legal case with a competitor over the potential theft of corporate secrets relating to its design. These slots have become incredibly popular, mainly because of their linked and progressive jackpot design. Their popularity has led to some US casinos setting up dedicated Lighting Links slot lounges, where banks of players can sit and play together. The more people who play together, the more the jackpot increases. This has been lauded recently for its innovation in bringing sociability to slot machines. The social casino version of these games allows players in jurisdictions where online slots are banned, like many states in the USA and Australia, to continue to play them albeit for virtual currency. It is a masterclass of brand continuity and maintenance. Bonus points are also given to people who allow their social casino accounts to be linked to Facebook, demonstrating additional value corportions derive from these games: data.

In the digital world, the acquisition and maintenance of data on individuals are integral to many company's portfolios. It is no different with social casino. Not only are social casinos themselves profitable enterprises, they create additional value by generating data on users interested in gambling and casino products. This is especially useful in jurisdictions where "for money" online casino and slots products are just starting to emerge. The largest of these emerging markets is the USA.

On a state by state basis, the USA is starting to allow online gambling, primarily online sports betting but some states, like Michigan and Pennsylvania, have legalised online casino and slot gambling too. For some analysts, the popularity of social casino in the USA could be explained by it filling a vacuum that real money gambling would have otherwise occupied. Other companies, particularly bricks and mortar casinos, also saw them as a way to extend their brand when customers were off site. As individual American states start to legalise online gambling, the companies who are best positioned to capitalise on this are those who already have amasses legions of data on people interested in these products, who are ripe to be "cross-sold" into real money gambling. Some companies are explicit about this aim. One notable example is Rush Street Interactive. On a recent webinar, Robert Picard, Rush Street Interactive's Vice President of Business Development, was clear that their database of users was their greatest asset and argued that i-gaming platforms should be built with real money in mind, of which user acquisition is a critical 
dimension. You can see these processes playing out in Rush Street's actions in Pennsylvania.

Back in 2015, Rush Street Interactive, aware of the potential opening of online gambling in Pennsylvania, launched their "CASINO4FUN" social casino in partnership with the local bricks and mortar casino, Sugar House. Speaking at the time, Richard Swartz, CEO, said "As Pennsylvania and other states contemplate legalizing online gaming, CASINO4FUN will provide our affiliated brick-and-mortar casinos with the potential opportunity to both convert play-for-fun patrons to playfor-real money players and increase the engagement levels of existing customers" (Business Wire, 2015). Whilst their Head of Marketing pointed out that the tie in with Sugar House casino meant the casino could keep their brand "top of mind" for online players. The point of CASINO4FUN was clear, it was the acquisition of data about users who would be ripe for conversion once "for money" gambling came and could bring brand loyalty for Sugar House. There appeared to be little pretence that Rush Street Interactive were interested in social casino for social casino's sake. It was a model they repeated in Michigan, opening CASINO4FUN in partnership with Gun Lake casino. Yet again, Richard Swartz was clear in his motivations: "As states move forward in legalizing sports betting and online gaming, our CASINO4FUN product provides our brick-and-mortar casino partners with the marketing opportunity to both increase the engagement levels of current casino customers and convert the play-for-fun social players into play-for-real money patrons should online gaming become legalized in their state" (SBC Americas).

Michigan has only just legalised online gambling so time will tell about the success of this conversion. However, Robert Picard was ebullient, arguing that Rush Street Interactive were the market leaders in online slots in Pennsylvania precisely because they had the data, power and product to convert people from social casino to real money gambling. Here the commodity of value is not the product, it's the database. What these examples show, however, is that concerns about migration from social casino to real money gambling are well founded. They are more than well founded; they are the bedrock of some companies' business models. Whilst the CASINO4FUN brand, with its link ups with brick and mortar casinos does undertake age-verification checks, others do not and it seems likely that underage engagement in these products continues. Yet, in policy and regulatory communities and certainly in academic circles, attention to social casino appears to be waning, 
despite us knowing very little about its impact and despite it providing excellent case studies of how businesses use gaming products to further their own commercial interests. Perhaps the growing legalisation of "for money" online casinos will render social casino obsolete-though data from Britain suggests that's unlikely. Perhaps the COVID-19 bounce will reinvigorate interest in the social casino market. Whatever happens, we should pay close attention.

\section{DAILY FANTASY SPORTS}

At an industry conference in 2019, the Chief Executive of one of the largest daily fantasy companies sauntered onto the stage, announcing that he "used be to the CEO of the largest daily fantasy sports company in America, but [is now] the CEO of the largest sports betting company in America". Whether true or not, this statement is an excellent example of the increasingly symbiotic relationship between gambling and gaming. Daily fantasy, for the uninitiated, is an extension of fantasy sports whereby people compete to pick the best sports team, drafting in a range of players, and get points for performance. People pay to compete and can win a number of different prize pools. The main difference with daily fantasy is that instead of doing this over an entire season, you can do it for a match, or for a single competition/tournament. There are different ways to win: you can compete head to head against someone else or enter competitions where you aim to be in the top $\mathrm{x} \%$ of all competitors. They have become exceptionally popular-it's estimated that in 2019 that around $9 \%$ of adult Americans engaged in daily fantasy sports (that's over 20 million people) (NCPG, 2019).

Originating in the USA, traditional fantasy sports have their early origins reaching back to the 1950s and 1960s, but really took off in the 1990s, when the internet allowed more rapid communication of results, points and connected thousands and thousands of people together. The thrill of fantasy sports was the ability to pick and manage your own sports team, pitch yourself against others and see how well you did. It was the ultimate game for sports fans, allowing you to be the manager and offering objective ways to judge performance. In the 1980s and 1990s, fantasy sports competitions were the analogue brother of emerging computer games like Football Manager or Championship Manager. Fantasy sports leagues could be organised locally or nationally. Their popularity spread beyond the USA. In the late 1990s my pal, 
Dominic, ran the Durham University Fantasy Football league, though it never occurred to me at the time to ask how he actually co-ordinated this - in the time before mass ownership of computers, it must have been a massive administrative task. But it was something he loved, proudly wearing his "Up the D.U.F.F" t-shirts around town. National leagues were co-ordinated through newspapers and the fantasy season lasted as long as the football season. In Britain, it even spawned a TV show. It was the ultimate football fans' game.

Season-long fantasy sports remains popular. Most major sporting leagues also run their own fantasy versions: there is the Fantasy Premier League, Fantasy UEFA league, Fantasy La Liga, the list goes on. And, of course, this is not just limited to football. The heart of fantasy sports lies in the USA, especially with baseball. Baseball was ripe for fantasy sports development. Avid baseball fandom is deeply tied to performance analytics and there is a strong tradition of using metrics to analyse individual performance. Baseball has even spawned its own statistical traditions: sabermetrics, whose increasing use coincided with the growing popularity of fantasy baseball. Attending one of my first baseball matches with a life-long Yankees fan, I was bewildered by the range of numbers that followed a player's name. She explained to me exactly what each one meant, though I was left none the wiser, but remember thinking here was a market ripe for sports betting - and not just sports betting but performance and in-play betting. The conditions would seem to be a perfect storm of statistical traditions, sports fandom and performance predictions. As it happens, the US market for sports betting, especially online sports betting, has been slow to arrive though is gradually appearing on a state by state basis. In the intervening time, the opportunities offered by developments in technology saw new forms of hybrid-fantasy sports emerge in the shape of daily fantasy products.

Just as the 2006 Unlawful Internet Gambling Enforcement Act (UIGEA) crippled the buoyant online poker market in the USA, the same Act carved out exemptions for fantasy sports, arguing that the results were based on the relative knowledge and skill of participants and not chance. In short, fantasy sports were not gambling, they were a skill-based game. Not long after, daily fantasy sports were born. One of the early entrants to the market explicitly acknowledged the emergence of daily fantasy from the ashes of online poker, stating that "The site will look familiar to many of you who are reading this blog because it's set up a lot like an online poker site" (Kang, 2016). Indeed, one commentator has noted how daily 
fantasy continues to incorporate the language, culture and ethos of online poker (Kang, 2016). The turning point for daily fantasy was the entrance of two venture capital start-ups into the market-one in 2009: FanDuel, the other in 2012: DraftKings. Between them, they would go onto share between 90 and $95 \%$ of the market. Heavy investment requires results and a raft of advertising, sponsorship tie ups and increasingly high-profile prize pots ensued. As did controversy. This included controversy about what amounts to the equivalent of "insider trading" for those that worked for DraftKings and controversies about fair play. This included concern about high-profile use of bots and scripts for players to gain advantages and the practice of, in the words of Jay-Caspian Kang (2016), "bumbunting" (this means really excellent players being matched up against novices, the outcome of which you can imagine). And, of course, debate continued about whether daily fantasy represented gambling or not, with some arguing the exemptions set out by UIGEA did not anticipate or include such rapid turn-around competitions. A few states agreed and either required daily fantasy to be licensed as gambling or outlawed it all together.

But this was not all. If daily fantasy sought to capitalise on poker markets that were no longer legal, especially by aping their look and feel, they also set up infrastructure to ensure they could capitalise on the longrumoured legalisation of sports betting in America. Yet again, the art of the cross-sell. The primary commodity these companies possessed was a large pre-existing database of people really, really into sports. Their platforms were set up so that data could be shared between different product verticals and, due to mass advertising and sponsorships, companies like FanDuel or DraftKings had high brand recognition - they became household names. When New Jersey became the first state outside of Nevada to legalise sports betting, it was FanDuel and DraftKings who emerged as market leaders. This was a strategic business decision. In 2019, the CEO of FanDuel's parent group stated:

our FanDuel brand and product proposition enabled us to take $50 \%$ of the sports-betting market in New Jersey....Cross-sell is an important contributor to our success, with around half our customers in New Jersey coming from our existing daily fantasy business, while strong cross-sales have delivered 15\% market share in online casino. We have recently gone live in Pennsylvania, where we are one of the first operators to launch online, and we hope to replicate our success there too. (Murphy, 2019) 
Other operators also saw the massive opportunities that daily fantasy companies could offer in terms of access to the US market. Paddy Power Betfair, one the biggest names in betting in Europe and Australia, bought FanDuel in 2018. At the time, Paddy Power Betfair were explicit in their motivations, announcing that the acquisition strengthened their ability to target prospective US sports bettors through the addition of a strong brand and large pre-existing customer base (Ahmed, 2018).

The success of daily fantasy in the US has long been associated with their betting laws, with daily fantasy arguably offering an alternative, legal, outlet for sports fans who want to express this through the wagering of money. In the early days, this notion was contested by industry executives who argued that daily fantasy served a different target audience to potential sports bettors. Yet, the marketing and business strategies of daily fantasy providers suggest otherwise. If these were such separate streams, with limited potential for cross-sell, large conglomerates like Paddy Power Betfair would not be that interested in them. And increasingly, this is not borne out by research. Studies in New Jersey showed that there was high degree of concordance between gambling and daily fantasy (Nower et al., 2018). Other researchers have shown how sports fandom, fantasy sports and sports betting are interlinked, with sports fandom being directly related to fantasy sports participation, which in turn was highly related to sports betting (Houghton et al., 2019). Of course, there will be some for whom daily fantasy is their thing-the one and only activity they are interested in-but it is also quite clear there is a high degree of interest in other forms of gambling too among daily fantasy players: something which companies have been eager to capitalise on.

But what about daily fantasy in other jurisdictions? Great Britain is an interesting case study here-especially in the context of its legal and mature online sports betting market. First, unlike the USA, there are no exemptions from gambling regulation for daily fantasy. It is categorised as pools betting and thus you need a gambling license to offer this. This, however, hasn't put companies off investing in daily fantasy in Britain, though it is arguably a minority pursuit. In fact, very little information about fantasy sports in Britain is available. Despite being regulated by the Gambling Commission, they don't report any data on it. In their annual statistics, only aggregate data across all pools licensees is given. And yet, there appears to be a growing interest in this, certainly by corporations. Paddy Power, off the back of its deal with FanDuel, launched Paddy Power Fantasy in 2019 and, echoing the moves of major broadcast 
corporations in the USA, Sky Sports launched a fantasy six-a-side game for every featured premiership match shown on Sky (though this proved to be short-lived). Despite this, Unibet also recently announced a move into daily fantasy, aiming to capture what they called "less bet-savvy" folk (as cited in EGR Intel). Daily fantasy companies like Sportico are the official daily fantasy sponsors of football teams like Queens Park Rangers, Burnley and Fulham whereas DraftKings became the daily fantasy sponsor of Arsenal, Liverpool and Watford. There is a hugely popular fantasy sports base in Britain, which intersects with sports fandom. Some football teams clearly see this as another way to expand their brand and further promote the notion of the "connected" fan (Hull \& Lewis, 2014). Broadcasters in the USA also invested heavily in fantasy sports, seeing this as a way to expand viewer numbers for certain games, moving beyond traditional fandom. Studies showed that audience numbers increased as daily fantasy did; if you are fantasy sports player you no longer only follow your traditional "team" but you follow your own fantasy team too.

What daily fantasy shows is how data, prediction, games and gambling coalesce around one product. The quantification of sporting data to look at performance is nothing new. Avid cricket fans look forward to the annual publication of Wisden's Almanack (first published in 1864) and the publication of the 1969 Baseball Encyclopaedia became the manual on which sabermetrics were developed. The difference, yet again, is speed, reach and access. The internet allows the fast exchange of data and information and big data processing power allows the synthesis of this into more rapid, meaningful results - it is for good reason that daily fantasy communities were upset about some players using computer scripts to gain advantage in competitions. The net result is to turn players into commodities, whose value change based on performance. These processes are epitomised by relatively new betting products offered by companies like Football Index who took this development to its logical conclusion. Operating with the tag line "fantasy football + stockmarkets + betting = footballindex", ${ }^{3}$ it ascribes values to individual players based on performance and people can bet on whether a footballer's "stock" will rise or fall. Their trading engine is provided by NASDAQ, who at the time of its announcement were effusive about expanding their trading platforms

${ }^{3}$ This is taken direct from Football Index's website. 
beyond traditional stocks and shares. It is the ultimate example of individualised commodification, where the stock is not a business but rather an individual. And it's easy to see the genealogical evolution of these games: which starts with the trading of football sticker packs (or baseball cards if you are in the USA), develops into games like FIFA Ultimate Team (arguably the online equivalent of tradeable cards) and fantasy sports and then transforms into Football Index. At the end of this process, the individual player has turned into a fully individualised tradeable commodity quantified by a system that defines their net worth. Considering football is ultimately a team sport, where fandom revolves around the club, it is an especially interesting lesson in individual commodification.

\section{ESPORTS}

On the 28 July 2019, parents of many British teenagers experienced a sinking feeling: Jaden Ashman, a 15-year-old lad from Essex, along with his gaming partner had just come second in the Fortnight World Cup Duos event. They netted themselves a prize of $£ 1.8$ million. Jaden's mum gamely admitted that she thought he'd been wasting his time and spoke of the battles they'd had about schoolwork. When asked what he'd do with the money, Jaden said he just wanted to buy his mum a house. This was no fluke, however. Jaden and his partner were arguably shock winners, but they had practiced for up to eight hours a day and employed a tactics coach for the world cup event. In the USA, the event gained widespread notoriety because the singles event was won by a 16-year-old boy, Kyle Giersdorf, who took home $\$ 3$ million dollars in prize money. At the time, the event, held in New York at the Arthur Ashe Stadium at Flushing Meadows (more famous for tennis than esports), offered the largest prize pool in esports: over $\$ 30$ million dollars, though its record did not stand for long-it was broken later that year by The International (the name of the annual DotA 2 world championship). To put this in context, this was a massively larger prize pool than offered by the Master's Golf Championship (estimated at \$11 million in 2019); the World Snooker Championship (around $\$ 3.5$ million) and was edging towards the prize pools offered by tennis tournaments like Wimbledon or the US open (over $\$ 40$ million). Over 23,000 fans attended the Arthur Ashe stadium to watch the three-day extravaganza and millions more streamed the event on Twitch (one of the most popular esports streaming services). Prior to the finals, there had been regional qualifying competitions and it was 
reported that over 40 million people worldwide attempted to qualify. There should be no doubt: esports is big business.

This, of course, was not the first esports event but it was one of the first to attract mainstream attention, especially mainstream media attention. A combination of high-value prize pools and the young age of its winners were perfect fodder to raise the profile of esports among those who quite simply may have missed this growing phenomenon.

The history of esports, as we now call it, reaches back to the 1970s-as soon as there were digital games, including consoles and arcades games, there was competitive gaming. One of the earliest recorded was the tournament held in 1972, hosted at Stanford University, where 24 players competed on the game SpaceWar. Called the Intergalactic SpaceWar Olympics, the prize was an annual subscription to Rolling Stone magazine (Larch, 2019). The introduction of permanent high scorers lists on arcade games naturally facilitated competition and by 1980 over 10,000 people took part in the World Space Invaders Championship. By the mid-1980s, an official book recording world records in digital games and pinball had been launched and competitive digital gaming was sufficiently mainstream that it was the focal point of the 1989 film "Wizard" (whose stars included Christian Slater) where three children travel across America to compete in a Hollywood video games tournament.

As technology developed, so did opportunities for competitive gaming. Focus switched to PC and console games and the ability to compete in teams, as well as solo. The StreetFighter competitions of the mid1990s gave way to team events in competitions focusing on game titles like Counter-Strike or Call of Duty, among others. Things developed further with Multiplayer Online Battle Arena games, where two teams of players compete against each other. Through this, titles like the League of Legends or Defense of the Ancients 2 (DotA 2) grew in popularity and became the cornerstone of esports competitions.

This brief review highlights that esports is a catch-all phrase for a number of different game competitions-whilst esports itself refers to competitive electronic games, there are different types of competitions, leagues and teams all vying for position across different game titles. Today, titles like DotA 2, League of Legends and Call of Duty form what might loosely be termed the "premier league" of esports tournaments, but there are multiple tournaments for multiple titles. 
Different leagues operate in different ways. For example, for esports professionals playing DotA 2, the pinnacle of the pro-circuit is "The International". Think Wimbledon for DotA 2 esports professionals. In 2019, over $\$ 34$ million was offered in prize money. Considering that the vast majority of this prize money is crowdfunded by a $25 \%$ contribution from sales of "The International" battle passes (each one costing a minimum of \$9.99) gives some indication of just how profitable this tournament is. There are open qualifying events, regional qualifiers, round robins, play offs, a group stage as well as the main event where the final 16 teams from across the world compete. The whole process takes a little under two months. Alongside the thousands who packed into the stadium in Shanghai to see the action, there was a total peak viewership of the finals of nearly 2 million people, watching on streaming services like Twitch or through YouTube or Facebook. These spectators accounted for over 88.8 million hours of viewership of this tournament (Yakimenko, 2019). As with Fortnight, it's big business.

What these examples show is the spread and reach of the esports world. It's an expansive, global and multi-billion-pound industry and one that is growing in popularity. Examples like Jaden Ashman and Kyle Giersdorf help raise its profile among mainstream audiences, as does coverage of esports events on television networks like ESPN or Sky Sports. Other events, like the COVID-19 pandemic, also further raised awareness of esports. In March 2020, the Bahrain Formula 1 (Fl) Grand Prix was replaced with the first ever virtual Fl race, complete with race commentary from esports pundits and a mixture of pro and celebrity participants. Shown on Sky Sports 1 in Great Britain but streamed via online platforms, its estimated that over 3 million people watched this race (myself included, and I have to confess I found it more fun than traditional Fl races), and the full series attracted 30 million views (F1, 2020).

Esports teams have sponsors, have managers, coaches, nutritionists and even specialist mental health services to aide often young competitors to cope with the pressures of their profession. Jaden Ashman, for example, was contracted to the Excel Esports team on the back of his Fortnight win, with a reputed salary of $£ 48,000$ per year. ${ }^{4}$ One year on and he has indeed bought the house he promised his mum.

\footnotetext{
${ }^{4}$ This was reported widely in newspapers who were doing a "one year on" story on Jayden.
} 
Some mainstream companies, sporting or otherwise, have long seen the potential of esports to extend their brands and promote fan engagement. The German footballing powerhouse FC Schalke 04 added esports to their portfolio in 2016, with a professional team (FC Schalke 04) playing in the League of Legends European Championship. Initially, FC Schalke had simply wanted to host an esports tournament at their staduim. By the time they had finished consulting with Tim Reichert, a professional footballer and esports pioneer, they had established their own team-Reichert selling them on the brand reach esports would provide. In a recent article Reichert stated that " $A$ lot of young people do not even know that we're a soccer club because they're just not interested. That's super important for attracting young people throughout our brand" (McCarthy, 2019). In sports, brand expansion and brand maintenance is a vital part of the economic model and FC Schalke hit on a novel way to reach a younger target audience.

Others have opted for the more traditional sponsorship route. Big name brands such as Red Bull, Renault, Honda, Gucci and Verizon along with more endemic companies, to name but a few, sponsor different esports teams. And now that esports has huge international reach, this opportunity has not gone unnoticed by the betting operators. Whilst mainstream attention has been focused on the increasingly symbiotic relationship between traditional sports and gambling sponsorship (e.g. over half of the British Premier League football teams now have gambling companies as a primary sponsor), a quiet revolution has been going on within esports. Of the top ten esports teams, ${ }^{5}$ three now have sponsorship link ups with gambling companies.

For some teams, like ENCE, this is a relatively recent occurrence, with new sponsorship deals signed with NitroCasino in July 2020. Like other global sporting conglomerates, ENCE (along with others) is more than just an esports team. It's a global brand. You can buy branded merchandise, they have their own YouTube channels and have their own media channels: ENCE TV, reportedly with over 4 million views. In the press release, announcing the tie in with Nitro Casino, ENCE's CEO announced that "Talking with NitroCasino on the idea of collaborating in creating great content around our Counter-Strike players had all of us excited straight away!" (Ence, 2020). Part of ENCE's mission is to

\footnotetext{
${ }^{5}$ The top ten esports teams were taken from a report by Ashton in the esports observer and then websites of each checked to identify sponsors.
} 
raise the profile of their players and give fans access to content relating to them-to create similar brand recognition to major league footballers. Whilst the nature of this sponsorship with NitroCasino remains to be developed, it is not inconceivable to imagine ENCE-based slot games joining the ranks of Brittany Spears or Elvis whose slot games proliferate Las Vegas casinos. Likewise, personal endorsements may follow and most importantly, sponsorship ties ins, give gambling companies like NitroCasino access to a massive network of fans at whom to market their products. Interestingly, NitroCasino is a relatively new entrant to the online casino market, which is notoriously competitive, relying on volume and player turnover to maintain market share. In a world when attracting the next generation of gamblers has mainstream gambling companies concerned, links with esports teams are an effective way to reach prime target markets. ENCE has already started publishing marketing material for NitroCasino, with one YouTube clip released on 17 July 2020 already garnering over 40,000 views.

Of course, this is not a new development-though perhaps is one of the more interesting recent moves with a brand ostensibly focused on casino and slots hitching their wagon to esports. Other sponsorship deals started around the mid-2010s-with Betway most notably entering into a major sponsorship deal with the high-ranking Swedish team Ninjas in Pyjamas (NiP). At the time, this was a considered a bold move, purely in financial terms. Such sponsorship does not come cheap. The partnership, initially commencing in 2016, was reported to pay each player a notable sum per month. Its renewal in 2018 was said to be for a seven-figure value (Fitch, 2018). The sponsorship rights include prominent positioning on shirts, onsite branding at training facilities, NiP/Betway esports social media channels and more. Of course, this gives Betway access to NiP fanbase for marketing. Betway have also established themselves as global leaders in offering betting on esports. On the day of writing (8am on a Monday morning) there were three live esports tournaments happening right now that I could bet on; all of which I could watch through the Betway website, via a live stream. On a Thursday afternoon, there were over 120 different esports bets on offer. Not only do Betway sponsor teams (they have expanded out from $\mathrm{NiP}$ to include a range of different teams in different leagues for different games), they also sponsor tournaments, being the primary sponsors of the ESL (formerly the Electronic Sports League) CS:GO tournaments. The Head of esports at Betway 
made their intentions clear "At Betway we remain committed to reaching and entertaining even more esports fans around the globe" (Fitch, 2019).

Key drivers which set esports apart from other more traditional sponsorship and marketing opportunities are both its reach in terms of audience profile and the technological ecosystem in which it is embedded. Esports fans tend to be younger and male, making them an extremely attractive target audience for betting and gambling companies. However, it is the technological ecosystem in which esports are embedded that really sets esports apart in terms of marketing opportunities. Yes, as Betway have shown, you can sponsor teams, have your logos on shirts, sponsor tournaments but the action for esports is in the streaming. Most esports are live streamed (and sometime those which aren't live streamed are presented as such), the most high profile platform being Twitch. The method of consuming esports by the typical fan isn't through the traditional models of watching via dedicated TV networks, it's through streaming services online. Relatedly, there is a whole community ecosystem, dubbed "participatory spectatorship", around which fans, stream, chat and connect all at the same time (Georgen, 2015). They do this through the streaming chat functions, through Twitter or by connecting with friends using specific communication software (such as Discord). Esports spectatorship is rarely a solitary, passive experience. Those streaming content for consumption don't even have to be esports professionals themselves; they can be super fans or talented amateurs. These streamers themselves have become powerful influencers, using their platform and profiles to connect consumers and brands (Miachon, 2018). The interconnected use of multiple different platforms for esports fandom and its highly digitally engaged fan base gives rise to innumerable opportunities for marketing.

The opportunities this affords have not gone unnoticed by betting and gambling companies and their marketing affiliates. Though this is not without controversy. Most recently, British research into gambling advertising, marketing and youth noted particular issues around esports. In their analysis, using a sample of data collected in 2018, researchers identified 44 Twitter accounts promoting esports betting which were responsible for sending out nearly 50,000 tweets, half of which were directly related to gambling and betting. The researchers found that $28 \%$ of users responding to these esports tweets were children under the age of 16 , and that $17 \%$ of users following these accounts were also children (Smith et al., 2019). Within their sample, the esports tweet which garnered most traffic was one from Betway advertising giveaway 
bundles for CS:GO. The report authors noted that this was likely a "name capture" exercise, a way of identifying accounts interested in esports that could be used for future marketing activity. The findings of this report generated consternation about young people's exposure and engagement with esports betting and gambling content, with the UK's Advertising Standards Agency (ASA) issuing an initial response and promising a fuller review. Whilst much of the ASA's initial response focused on scope (many of the promotions and tweets were not facing to British audiences and were, therefore, deemed to be "out of scope"), the ASA did at least affirm that advertising and marketing standards which apply to traditional sports should be considered to also apply to esports (ASA, 2020). Notably, they affirmed that esports marketing should not feature anyone who looks under 25-a challenge for a sporting sector where champions can be in their teens.

Betway were not the first bookmaker to offer esports betting but they were, arguably, the first to capitalise on the unique marketing and branding opportunities offered by esports. Where they started, others have followed. Unibet became the official betting partner for team Astralis in 2018 and though there is debate within the esports community as to whether such sponsorship should be allowed, it seems likely that this process will continue. Whilst the benefits for the gambling companies are clear, so too are the benefits for esports teams. Sponsorship funding has clearly enabled some to help grow the sport and, sometimes, continued sponsorship is contingent on this occurring. Betway's 2018 sponsorship renewal of $\mathrm{NiP}$ hinged almost entirely on NiP adding a high-quality DotA2 team to their roster (Fitch, 2018). This was a two-way process: Betway's funding enabled this to happen and their continued sponsorship was contingent on this, opening up DotA 2 leagues and markets for their brand. As is evident in traditional sports, it appears there are increasingly co-dependent relationships between some gambling companies and the development of esports teams as global brands and enterprises. Yet again, whilst most mainstream regulators, academics and politicians have been focused on football, and on the attendant normalisation of gambling that this may bring, these same processes have been embedding themselves into esports communities, with little mainstream comment. In the UK, at least, this may be changing with esports considered as part of the gamblification of sports within a recent House of Lord's Select Committee report on the gambling industry. Though it is worth noting that the House of 
Lord's primary recommendations still focused on ending the sponsorship relationship between football and gambling (House of Lords, 2020b).

Given the projected growth of esports and esports betting, this is likely to attract increased regulatory and policy attention. This is already starting. The designation of COVID-19 as a worldwide pandemic precipitated unprecedented changes in behaviours, the effect of which is we are still experiencing and may be long lasting. The initial COVID-19 lockdown saw the cancellation of many major sports events worldwide and bookmakers braced themselves for a major downturn. A noted side effect, however, was an increased interest in esports. Yes, esports too had to adapt - no longer could tournaments be held in arenas with players sitting side by side, but with some adaptation, teams could and did compete. Mainstream recognition of esports came with the likes of Fl and Nascar creating esports races to replace the real thing. In Britain, at least, the bookmakers were quick to seize the opportunity. I sat watching the first Fl virtual race on March 22 2020, monitoring the odds offered on the race by a major British bookmaker who previously had little to no portfolio for esports. Their odds tracked performance as the race progressed and updated accordingly. This was really an entry-level introduction to esports, a way to continue to engage Fl fans when nothing else was available but, of course, the standard esports tournaments also kept on going.

According to the UK Gambling Commission, betting on esports drastically increased during the initial COVID-19 outbreak (albeit from a relatively low base): in March 2020, gross gaming yield (that is the total amount lost by punters to bookmakers) on esports bets in Britain was around $£ 1.5$ million, this rose to $£ 3.4$ million in April 2020, and to $£ 4.6$ million in May. Data for June showed the beginnings of a retraction, dropping back to $£ 3.5$ million and a further fall to $£ 2.5$ million in July-but taken together, over $£ 14$ million was lost on esports betting from April to July 2020 in Britain alone (Gambling Commission, 2020). Considering that the Gambling Commission estimates that just $£ 50,000$ was lost on esports betting in March 2019, there is tremendous growth in this sector. Whether trends return to pre-COVID-19 levels once other live sports return remains to be seen.

With an emerging sector like esports, consideration naturally turns to who these bettors are. Empirical investigation is nascent and there are few estimates about which we can be confident. Studies have tended to show that esports bettors are more likely to be male, to be heavily engaged in 
esports and video gaming, and to be heavily engaged in other forms of gambling. My own study estimated that in 2019 around 3\% of young people aged 16-24 in Britain had bet on esports in the past year (Wardle et al., 2020). To many that may seem a very low number, and that esports betting is a niche activity. But it is not when considered in context. Those aged 16-24 aren't actually that engaged in gambling generally. Well over half of the participants hadn't gambled at all and engagement in most forms of gambling remained a minority activity. Only buying scratchcards, lottery tickets and sports betting reached double-digit figures for participation. This means that among this age group, betting on esports was as popular as many other "traditional" forms of gambling, such as visiting casinos, betting in bookmakers or playing machines formerly known as Fixed Odd Betting Terminals. Whilst this may say much about the decline of "traditional" gambling, it shows the relative popularity of esports betting among young people who do gamble.

Furthermore, these esports bettors had a very particular demographic profile-they were more likely to be male and to be from non-white ethnic backgrounds. They were also far, far more likely to experience problem gambling and to be very engaged in digital games, especially gambling-like practices that are embedded within digital games (like loot box purchases or skin betting). Indeed, when it came to identifying those most likely to be esports bettors, it wasn't necessarily how often young people played digital games themselves that was important, but rather what other types of gambling-like practices they engaged in, such as the betting of skins or opening of loot boxes (more on which later) (Wardle et al., 2020). This is just one preliminary study but there appears to be a whole ecosystem in which esports bettors are embedded which may encourage or facilitate certain forms of gambling and gamblinglike practices. These practices themselves are increasingly associated with harms.

And it's not just online gambling companies getting in on the esports action. Traditional bricks and mortar casinos have also jumped on the esports bandwagon. In 2019, attending an international gaming industry event, two esports entrepreneurs announced that esports events were the "training ground for future wagerers". 6 Sitting in the audience, I was staggered that two industry professionals would be quite so brazen. I

\footnotetext{
${ }^{6}$ Although these comments were made in a public forum, attribution of them has been anonymised.
} 
asked them to repeat this, which they did, and queried whether they thought this was OK given that so many esports fans attending tournaments were not of legal age to gamble. They blustered and argued if you weren't of legal age to gamble then it doesn't matter as you wouldn't be able to place a bet-so what's the harm? These two industry executives, working for the same company, were selling a product. Their product was running and placing esports tournaments within traditional bricks and mortar casinos as a way for casinos, especially US-based casinos, to stay relevant to the younger generation. Their comments were part of their sales pitch and should be viewed in this context-though when they spoke about the benefits of children attending esports tournaments in casinos as a way to evoke positive brand associations between the casino and the child, you got the impression they meant it. Of course, these tournaments are not held in the casino itself, but in the conference centres or ballrooms. Whilst these two professionals may have been the latest to expound the value of esports for bricks and mortar casinos, they certainly weren't the first.

Back in 2016, Downtown Casino on the Las Vegas Strip was the first casino to take wagers on esports events and set up a dedicated esports lounge. Other casinos followed suit, opening dedicated esports arenas. Casinos executives have long been worried about the trend for millennials to display less interest in gambling than their predecessors, and particularly less interest in slot machines, one of their most profitable products. According to one US-based report, gambling was seen as less important to millennials than other generations, and crucially, the generation who had grown up with digital games perceived traditional slots as dull compared with the type of immersive games they were used to (Bokunewicz, 2016). Where was the element of skill, of control, where was the narrative and the immersive experience? Slots have changed little and findings like this give casino executives, and slots manufacturers, cause for concern. Part of the industry's response has been the development of skill-based slot machines, which offer bonus rounds where the players can interact with the game to win more money (though the house will ultimately always win). But part of the reaction has also been to focus on activities that this generation, and the next, are highly engaged inand that means a focus on esports. This isn't, however, easy. It requires sustained investment and cultivation of partnerships-a one off tournament is unlikely to bring the kind of rewards that industry executives seek. It needs to be part of a longer-term and sustained strategy, as one leading 
casino industry executive stated "if you want to put esports in your casino, you have to have skin in the game". T The rewards, though, are potentially significant, if indeed esports are a training ground for future wagerers. Given this, it is likely that partnerships between land-based casinos and esports may continue to grow.

What the example of esports shows is how interconnected gaming and gambling corporations can and have become. Like social casino and daily fantasy sports, they are a way for gambling corporations to engage with and to identify large segments of the population who may be interested in their products and to market to them, or to reach large numbers people who could be cultivated to become interested in their products. This is the ultimate in cross-selling-identifying people with an interest in esports and attempting to get them interested in betting on this too, reframing fandom through the lens of gambling. Or an attempt to reach notoriously difficult age groups to pitch them the excitement of the casino and build brand loyalty. Many of the connections already made between sport fandom, clubs and gambling companies for football are equally evident for esports. If national governments are concerned about this for football, they should be equally so for esports-given the huge audiences this commands and demographic profile of these fans. Yet much of this exists under the radar-the place in which esports is conducted and watched is not visible to most, and certainly not to non-fans. This shields these developments from the view of many but the same processes are at play. There is the potential for esports and gambling to develop a level of co-dependency currently and controversially witnessed within mainstream sports, and evidence of gambling corporations capitalising on the access that esports offers to typically hard to reach groups for their own business needs.

\section{Skin Gambling and Betting}

So far, when looking at esports, we've covered the kind of betting that happens for real money: a more traditional and familiar model. But money is not the only collateral that can be used to bet on esports. This is where we turn our attention to skin betting and gambling. Skins are a commodity unique, though not without parallel, to the world of digital

${ }^{7}$ Quote not attributed to maintain anonymity. 
games. Whilst skins exist for a variety of games, it was their addition to the Counter-Strike titles that heralded the start of a new economic market for them. In August 2013, Valve (producer of the Counter-Strike family of games) launched its Arms Deal Update which added decorative weapon "skins" to the game (Greer et al., 2019). A skin, quite simply, is a decorative item which players use to customise their weapons or characters. In the case of Counter-Strike games, played from a first-person perspective, it's a decorative item for your weapons. In some respects, it is not dissimilar to children dressing Barbie or Action Man with different accessories.

Except that it is so much more than this. Some of the skins are rare, exceptionally rare, and that gives them enormous value. Along with this value comes prestige, where players within a community want to demonstrate their skills and build esteem by owning the most valuable skin. And the values are astonishing. Being shown around an esports tournament by a colleague, she pointed out the skins possessed by each competitor displayed on the screen. One player, she noted, owned one of the most valuable CS:GO skins available, worth over $\$ 40,000$. Of course, not all skins command this value, but some are worth thousands and it is not uncommon for some players to have hundreds of pounds invested in skin inventories. All of this has been enabled by the growth of an economic ecosystem for the buying, selling and trading of skins. Very simply, alongside the CS:GO games there sits another website where people can purchase skins and other in-game items and transfer them to their CS:GO characters. This interface is called the Steam Community Market and, just as the name implies, it works like an online marketplace. Whilst there is a limit on the value of skins that can be traded on this marketplace, it has an open Application Planning Interface, which means that other websites can link up with Steam and skins can be digitally transferred from one marketplace to another. From there, there is no cap on the value of the skin, that's determined by market forces (i.e. the community of players) and the rarity of the skin.

Instinctively, this invites parallels with the trading of other commodities, like the so-called Tulip Bubble of the mid-1600s where fortunes were spent procuring and trading future contracts on the most decorative and rare tulip bulbs. Fortunes were made and lost-spectacularly so when in 1623 the price of tulips dropped dramatically and unexpectedly. The impact of the "Tulip Bubble" crash has been hotly debated, but if nothing else, this episode emphasises how the economic value 
of some commodities are bound within community systems in which power, privilege and aesthetic preferences determine worth. The shock of the tulip's sudden demise was considerable, and a whole network of values were thrown into doubt (Goldgar, 2018). It is tempting to view the trading of skins in a similar way-as a bubble which may yet burst. Yet, another way of thinking about skins is as a form of electronic art. Few skins are completely original, but like limited edition artworks, they maintain a monetary value dictated by supply and demand, underpinned by communal values of worth. Without the community subscribing to a common set of values that are given to individual skins, the market would not exist.

Why is this? Within gaming communities, skins are culturally important artefacts. The possession of them confers status. Within these highly competitive worlds, this gives them an intrinsic value, of which public display is an important component. I first noticed skins when playing Stick Hero, a super simple game the purpose of which was to successfully get my character from A to B. As I did so, I could collect "cherries" along the way. The game displayed a "cherry" counter letting me know how many I'd got. And the number of these cherries sometimes increased of their own accord (I later found out it was linked to how often I played). Curious, I looked up what the cherries gave me-it was access to a marketplace where I could use the cherries to buy new outfits for my character or change my character altogether. If I didn't want to collect the cherries, I could just buy them (the going rate is $99 \mathrm{p}$ for 400 cherries). Being miserly, I didn't bother: who else was going to see my character and didn't he look just fine the way he was? But this was a game that only I played. Dressing him up really would have been the equivalent of me changing Barbie's outfit. To my mind, there was no one else to see him, so really what was the point? But other games, especially multiplayer action games, are specifically designed for players, their avatars and their weapons to see and be seen. These games are a spectacle and it is the embedded nature of this spectacle from which skins both derive and confer value.

Of course, this isn't the only way in which skins gain value. They may be pieces of electronic art, they may confer power, prestige and status but they are also a form of currency. At an industry conference, a leading esports betting executive described skins as cryptocurrency, stating "once 
you have it you can do what you want with it". ${ }^{8}$ And he's not wrong. Once skins were launched, a whole network of secondary marketplaces for them quickly developed. Interestingly, the skin itself is still technically the property of the game producer, but trades of these items are perfectly possible. These secondary marketplaces included websites which allowed people to sell skins for the currency of their choice. But also, a whole range of gambling sites sprung up, where the skin itself could be used as collateral for betting. This included lotteries, casinos games and betting on esports itself. All unregulated, all accessible to minors. And popular. In 2017, it was estimated that $11 \%$ of British children aged 11-16 had bet with skins (Gambling Commission, 2017a). Huge estimates of value were placed on skin betting, with Grove estimating that $\$ 56$ billion would be traded on skin gambling in 2016. But 2016 quickly became infamous for other reasons: the year of the skin gambling controversy. As a completely unregulated industry, a raft of shady practices were brought to light. This included YouTube influencers revealing how skin betting websites altered their chances of winning when filming promotional videos so that their products would seem more attractive. Other influencers were recommending skin betting websites without disclosing that they actually owned the websites they were promoting (some of these videos were reportedly viewed over 5 million times). And an entire esports team bet against themselves on the skin betting market, throwing their match.

As with social casino, regulatory, policy and legal interest was piqued. In 2016, class action lawsuits against Valve were issued for sustaining illegal gambling markets and, yet again, Washington State led the clampdown, issuing a letter to Valve stating that they needed to stop facilitating the skin gambling market. Valve's response: prove it. However, Valve did then send cease and desist notifications to over 40 skin gambling websites, though it was not entirely successful. As with social casino, the question centred on whether a skin was a thing of value. Interestingly, in this area, the British regulator moved beyond a "watching brief" status and took regulatory action against two individuals running the skin betting website FutGalaxy.com. The owners were prosecuted for running an unlicensed gambling website which was taking bets from minors. In summarising the

\footnotetext{
${ }^{8}$ Note as previously, attribution of these statements has been anonymised, despite being made in a public forum.
} 
case, the District Judge said he was horrified to see footage of children as young as 12 betting on their website (Gambling Commission, 2017b).

The basic operation was that players bought FutGalaxy coins, a virtual currency, on this website. These could then be wagered on a whole range of gambling products offered by the website. Winnings were paid back in virtual currency. These could then be exchanged for FIFA coins, which in turn could be converted into real money by trading FIFA coins on another third party website (a website that one of the owners of FutGalaxy also had a financial interest in) and to which the original website directed you. The Gambling Commission took exception to this, arguing that as soon as you provide the facility to convert the virtual currency to real currency, this is no longer just gaming, it becomes gambling because the prize has a real "money's worth" value. The Gambling Commission were unequivocal, stating that "all interested parties should be clear, that where gambling facilities are offered to British consumers, including with the use of in-game items that can be converted into cash or traded (for items of value), a licence is required" (Gambling Commission, 2016). FutGalaxy's owners avoided jail but did have to pay over $£ 200,000$ in damages.

What this episode demonstrates is the speed with which new markets and products can emerge and the complexity of the ecosystems in which these transactions are embedded. Don't forget, it was only 2013 when skins were launched and by 2016 , this had given rise to class action lawsuits, regulatory investigations and court cases, and Valve, in particular, was feeling the heat. Valve denied that they had, or have, any role in facilitating these gambling markets (and to be clear, they and their products were not involved in the FutGalaxy case). Yet, it was Valve's infrastructure that allowed many of these markets to exist in the first place, and their actions that generated this gaming ecosystem. Perhaps sensing the needed to, at least, be seen to do more, Valve took further action and in 2018 implemented a seven-day trading ban on skins, meaning that people had to wait seven days before skins could be re-traded. This was announced as a crackdown on scams and fraud, but it had the effect of cooling the skins gambling market too, which relied on fast and high volume turnover. Many in the CS:GO community were aghast, especially those traders who made their money trading skins. Just like any market shock, there was an initial period of panic as some sold off their inventory, 
whereas others implored people to hold firm and ride it out. ${ }^{9}$ At the time of writing, the trading ban still exists and whilst there has undoubtedly been an impact on what might now be termed the "traditional" skin gambling market, new products have already emerged. As colleagues Abarbanel and Macey (2019) have traced, a new form of skin market (termed VGO skins) has emerged, that is devised and distinct from the games producers and underpinned by blockchain technology. These types of skins are already being accepted as collateral for gambling by specialist websites, including firms like the Polish start-up Thunderpick. ${ }^{10}$

Whilst the trading ban may have cooled the skin betting and gambling market, it has not decimated it. The market still operates, still unregulated, still subject to few age-verification checks and still popular. Notably, the latest British Gambling Commission data showed that $6 \%$ of children aged 11-16 had ever bet with skins, either privately with friends or on external websites, demonstrating children's continuing ease of access to this (Gambling Commission, 2019). Evidence from my own research shows that around $5 \%$ of 16-24-year-olds had bet on external websites with skins in the last year. This may seem relatively small scale, but when viewed in context, this makes betting with skins as popular as playing slot machines $(6 \%)$, playing online casino games or slots $(4 \%)$ and more popular than playing table games at a casino (3\%). The young people who bet skins had a very particular profile: they were much more likely to be male, though around a quarter were women. They were more likely to be aged under 21 than over and were somewhat more likely to be from non-White ethnic groups. But these people were not just skin bettors alone, they were deeply engaged with a whole range other gamblinglike mechanics within games: the majority reported buying loot boxes for money, with around one in three saying they did this often; they

\footnotetext{
${ }^{9}$ There are some exceptionally interesting threads on Reddit about this, one example of note was where a user claimed: we are the market, if we hold firm and don't panic, the market will survive!

${ }^{10}$ Thunderpick are an exceptionally interesting firm. They are clearly a gambling firm but their founders have quite deliberated aped the look and feel of esports platforms; they offer in-play esports betting, skins as collateral and operate a points-based loyalty system by which people can gain points by embedding the Thunderpick name within their user handlers on websites like Twitch, etc. Thunderpick will give you points for continuing to do this and will check that you continue to do this in order to receive your points. See their website: https://thunderpick.com.
} 
gambled skins privately between themselves and others and they used ingame items to open loot boxes also. Over a third had also bet on esports in the past year. In short, young adults who gambled with skins were very, very engaged in a range of gambling-like features associated with digital games. Perhaps, unsurprisingly, given how engaged in gambling and gambling-like products these people seemed to be, the proportion of them experiencing problems with gambling was exceedingly high: two out of five skin bettors displayed problem gambling behaviours. Equivalent estimates among those who did not bet skins were one out of fifty-a marked difference (Wardle, 2019).

In the past, there have been entire campaigns launched against particular products where a strong association between engagement in that product and problem gambling has been shown. In Britain, this recently focused on so-called Fixed Odd Betting Terminals (FOBTS), where people could place bets of up to $£ 100$ per spin on machines within local betting shops. Around 3\% of the population played these games and about $10 \%$ of those who played them experienced problem gambling (Wardle et al., 2011). There was a sustained and ultimately successful campaign to change these machines and reduce the maximum stake that could be bet on them. A similar campaign has now been launched for online slot games. Yet, in Britain at least, we appear to have some emerging evidence that among young people skin betting is more popular and more strongly associated with problem gambling than either FOBTS or online casino games. Yet very little policy attention has or is being paid to this issue. A recent Select Committee report by the House of Lords was dismissive on this topic, stating that skin gambling is regulated by the Gambling Commission and as such that was sufficient (House of Lords, 2020b). There was no further discussion of it as an entity or as something specifically worthy of concern. Instead attention focused on loot boxes, the new poster child of gaming/gambling convergence.

\section{LOOT BoXes}

That is what we look at as surprise mechanics. It is important to look at this. If you go to-I don't know what your version of Target is-a store that sells a lot of toys and you do a search for surprise toys, you will find that this is something people enjoy. They enjoy surprises. It is something 
that has been part of toys for years, whether it is Kinder eggs or Hatchimals or LOL Surprise! (House of Commons, 2019)

Kerry Hopkins, the Vice-President for Legal and Government Affairs for EA games, when addressing the UK Select Committee Inquiry into Immersive and Addictive Technologies probably thought she was making a fairly innocuous comment - that loot boxes in games operate according to the same kind of "surprise mechanics" that have been part of other toy brands for years. If she thought this would take the heat out of the debate, she was wrong. Her statements made headlines the world over. People lined up to talk to journalists about just how wrong this comparison was. Not least, because the prize within a kinder egg is fixed at the point of manufacture - not so with loot boxes, whose content can be algorithmically generated and thus changed at the point of purchase. Within gaming communities, this attempt to rebrand loot boxes as "surprise mechanics" and "quite ethical" became a major meme, with users posting numerous parodies (my personal favourite: being laid off isn't job loss, it's just a "surprise" vacation!).

But quite how did we get here? Where a function within a video game ended up be hotly debated among Members of Parliament, who at times were clearly struggling to comprehend the complexity of the gaming ecosystems they were charged with investigating. How did we get to a point where a gaming executive thought a good way out of a tricky situation was to draw parallels with other toys (one somewhat suspects that if you told the average gamer that they were just playing with toys they may seriously object to this classification) and where both mainstream and social media lined up to tell EA games quite how wrong they were.

Until 2017, it is unlikely the term loot box was part of many people's vernacular (and to be fair, still may not be for some). But since then, loot boxes have become front-page news and regularly make headlines. The catalyst for this: Star Wars: Battlefront II. A game so maligned in testing for its seemingly cynical use of loot boxes that the developers, EA games, dropped this aspect before the game was even launched. Even so, gamers were outraged - the original design pretty much meant that those who didn't purchase loot boxes were seriously, seriously disadvantaged. According to one colleague, you'd have to play for over 6000 hours to achieve the same outcome without buying a loot boxes (Johnson, 2019). EA games may have removed these features but the damage was done, 
and this proved to be the lightening rod around which growing disquiet about some of these products made it into mainstream attention.

Yet loot boxes are not new. In Asian games, loot box mechanics were introduced in some games from the mid-2000s. In Western jurisdictions, the first popular loot box is generally accredited to the game Team Fortress 2, where Valve introduced the ability to open crates containing unknown rewards using purchased keys. At the same time, FIFA released its Ultimate Team title, in which success broadly relied on purchasing packs to put together your ultimate team. From then on, loot boxes were added to more and more titles and became increasingly controversial (Zendle, Meyer, \& Ballou, 2020). By 2018, it was estimated that 71\% of game play sessions were on games which contain loot boxes (Zendle, Meyer, Cairns, et al., 2020).

But what are loot boxes? In the words of my colleague, David Zendle, they are: "items that may be bought for real-world money, but which contain randomised contents whose value is uncertain at the point of purchase" (Zendle, Meyer, Cairns, et al., 2020). This, however, masks a deep variety of loot boxes, which are embedded into games in different ways. In some games, the contents of the loot box can either be won or purchased. In some games, you can still get to open loot boxes through grinding away at the game or achieving certain milestones (which can sometimes include how often you've engaged with the game) or you can choose a shortcut and pay for it. Others, you can only pay for. In some games, the items you win are just cosmetic - something to add to your inventory of skins-or include certain modifications you can add to your character, like poses or something to adorn your profile, none of which affects your game play. And, of course, in some games there is a whole secondary network which facilitates the trading of these items. Some other games, however, compensate people if they open a loot box and it contains an item they already have. In other games, the content of the loot box can give you in-game advantages. These mechanics have led to a whole host of controversies among gaming communities-are they fair? Are they ethical? And among more mainstream commentators-are they gambling?

This latter debate focuses on the fundamental mechanics that underpin loot boxes: someone pays to open a box or crate for the chance of winning something of value. What you get for your money is utterly uncertain: you may get a skin or card that is really valuable or you may get something that is nearly worthless. You do, however, get something. Crucially, the probability of getting rare items is often not the same as the probability of 
getting common items. The probabilities are controlled and determined by the game producer and often are not made clear to the gamer. Until recently, the game Overwatch has been relatively unique in making the odds of obtaining common, rare, epic or legendary prizes (their classification) transparent, with the odds of receiving a common prize being slightly less than 1 in 2 and of obtaining a legendary prize being around $l$ in $40 .^{11}$ In some games, you open the same loot box over and over in the hope of obtaining the item that you want. It is not always clear how game developers control these choices and if the reward algorithms operate in a fair and transparent way. A recent study in Australia which reviewed patents pending for a variety of digital games found evidence of game developers using machine learning to encourage repeat in-game purchasing (King et al., 2019). Though as one games developer pointed out, this can sometimes work to the gamer's benefit, as they programme in a "pity timer" whereby if someone has repeatedly opened the same box to get a rare item, after the nth opening they will give it to them (Cerulli-Harms et al., 2020). This may sound magnanimous, but the example given was the 'pity timer' kicking in after 100 goes-at around $\$ 1$ per go, that's a lot of money spent before the heartstrings of the developer are tugged. But the long and short of the situation is that we really don't know what mechanics underlie these products or how and if games developers use the vast insight they hold on players to change reward mechanisms or to push gamers to further purchases. From a consumer protection point of view, this is concerning.

Because of the variety of loot boxes available and the different ways they have been embedded into games, regulators and researchers alike have tied themselves in knots trying to identify the set of circumstances under which loot boxes may constitute gambling. A further complication is the variance in national definitions of gambling and how "value" is defined. Belgium, for example, famously banned loot boxes because they determined that it didn't matter whether the prize offered was monetary or not, it was gambling. The Dutch did the same but for a different reason-here it was the fact that the prize had a market value and could be traded that made the difference. The UK regulator has been much more reticent, arguing that generally loot boxes operate within a closed system and therefore don't represent a money's worth prize-handily

${ }^{11}$ These are published on the Overwatch wiki: see here: https://overwatch.fandom. com/wiki/Loot_Box. 
side-stepping issues with games where the items won in loot boxes can be traded on third-party websites for fiat currency-the very arguments they relied on when prosecuting FutGalaxy for illegal skin gambling.

A recent European Commission report stated that to be defined as gambling, loot boxes must involve the outlay of money (Cerulli-Harms et al., 2020). And when looking at the potential impact of loot boxes, this does appear to be a distinguishing feature. In a recent British study of 1624-year-olds, it was people who purchased loot boxes with money rather than those who obtained them through game play or in-game items who were more likely to experience problem gambling. Opening loot boxes with in-game items/currency was popular: over one in three participants did this. Paying money to open them was less so, with around one in ten doing this (Wardle \& Zendle, 2020). This association between paying real money to open loot boxes and gambling problems has been replicated in other studies, conducted in a range of countries. A number of explanations have been offered to explain this association: perhaps people who pay money to open loot boxes are just much more impulsive than those who don't, which also happens to be strongly associated with problem gambling. Yet this study took impulsivity into account and the association still held true. Perhaps, it has been suggested, that people who buy loot boxes are just really, really into gambling - they probably gamble on lots of other things and the purchase of loot boxes may simply be a further manifestation of this interest (Gainsbury, 2019); you have to be really into games of chance to think that the purchase of loot boxes are worth it. But yet again, this study took this into account too and the results were the same-there remained a strong link between the purchase of loot boxes and problem gambling (Wardle \& Zendle, 2020).

There is, however, so much we still don't understand about this relationship and given that looking at behaviours and behaviour change over time is needed to really unpick what is going on, it seems unlikely that this will be resolved anytime soon. This association with problem gambling is far from the only issue with loot boxes either (King \& Delfabbro, 2018). There are real questions about consumer protection-are they fair, are the mechanics being manipulated, are they ethical, are they necessary, are they fun, are they conditioning young children in the ways of gamblinglike mechanics, are they normalising games of chance in a way that could influence subsequent behaviours? The list goes on. Most recently, the European Commission grabbled with these thorny questions, including that of whether loot boxes should be defined as gambling (Cerulli-Harms 
et al., 2020). They, rather sensibly, came to the conclusion that perhaps this was the wrong question and that instead we should be looking at the fuller range of practices associated with these products and questioning what was the risk of harm to consumers. They are right. Experience tells us that arguing over definitions of gambling can leads us round in circles until they become tested points of law. As we saw with social casino, this takes time and even then provides little clarity as legal definitions are the preserve of individual states and national governments. In the meantime, the products continue to exist, researchers continue to argue about correlation vs causation and calls are made for longitudinal studies or objective data (which don't then materialise) to settle the debate. If we've learned anything from the experience of social casinos, it's that the debate needs to be reframed and consumer protection looks a promising way to do this.

\section{Key LesSONS}

These examples, far from exhaustive, exemplify a range of processes. First is the increasing intersection between gaming and gambling companies, with each seeking to learn and capitalise from each other. Data about users and potential users is a key commodity for both. Such data-driven customer acquisition and retention thus generates the conditions for these two sectors to co-operate, innovate, in some cases exploit but also learn from each other. Second, these examples also show us how quickly the development of new industries disrupt and challenge our existing thinking and legislative frameworks. Ten to fifteen years ago it feels inconceivable that we would be debating the value of the virtual and seeking to assess whether digital currency or digital items had a worth beyond their contextual origins. Third, we also see the increasing difficulty of thinking about these developments in purely national terms. The gaming/gambling ecosystem created transcend national boundaries, complicating our understanding of them and actions within them. In this context, the work of the European Commission suggesting a cross-national approach is welcome. What is certain, the examples outlined above should not be considered in silos, but rather considered as connective elements within a growing gaming/gambling ecosystem. To date, we've tended to think about these issues as discreet challenges, moving on from one to the next as public or political opinion dictates, never quite finding the answers we seek. We need to pay more attention. More attention to the broader systems in 
which these products are developed, more attention to the processes that determine their advancement (that loot boxes became a mainstream issue because someone "messed" with the Star Wars game is a truly terrifying thought) and more attention to impact-reaching beyond questions of whether something is gambling or not.

\section{REFERENCES}

Abarbanel, B., Macey, J. (2019). VGO, NFT, OMG!: Commentary on continued developments in skins wagering. Gaming Law Review, 23(1): 23.

Advertising Standards Authority. (2020). Responding to new challenges: Gambling, esports and social media. ASA.

Ahmed, A. (2018). Paddy Power acquires FanDuel. Financial Times. Available at: https://www.ft.com/content/2bbcabfa-5ea6-11e8-ad91-e0laf2 56df68. Accessed 17 August 2020.

Blaschke, B. (2019). Social casino key to Aristocrat's 2019 growth strategy: Croker. Inside Asian Gaming. Available at: https://www.gamblinginsi der.com/news/209/aristocrat-purchase-product-madness. Accessed 2 August 2020.

Bokunewicz, J. (2016). Millennial entertainment preferences study: Final report 2016. Galloway, NJ: Stockton University.

Business Wire. (2015). Rush street interactive launches online CASINO4FUN for Philly's SugarHouse Casino. Business Wire. Available at: https://www. businesswire.com/news/home/20150928006515/en/CORRECTING-REP LACING-Rush-Street\%C2\%A0Interactive\%C2\%A0Launches-Online-CASINO 4FUN\%C2\%A0for\%C2\%A0Philly\%E2\%80\%99s\%C2\%A0SugarHouse-Casino.

Accessed 5 August 2020.

Castronova, E. (2005). Synthetic worlds: The business and culture of online games. University of Chicago Press.

Cerulli-Harms, A., et al. (2020). Loot boxes in online games and their effect on consumers, in particular young consumers, Publication for the committee on the Internal Market and Consumer Protection (IMCO), Policy Department for Economic, Scientific and Quality of Life Policies. Luxembourg: European Parliament.

Ence. (2020). ENCE and malta based iGaming brand NitroCasino start a partnership focusing on creating fun and engaging content for all ENCE fans. Press Release July 1, 2020. Available at: https://www.ence.gg/article/encex-nitrocasino-for-your-entertainment. Accessed 13 September 2020.

Fitch, A. (2018). Betway and Ninjas in Pyjamas extend partnership with seven figure deal. Esport Insider. Available at: https://esportsinsider.com/2018/ 10/betway-ninjas-in-pyjamas-extend-partnership/. Accessed 9 October 2020. 
Fitch, A. (2019). Betway extends sponsorship of ESL through 2019. Esport insider. Available at: https://esportsinsider.com/2019/02/betway-esl-sponso rship-extension/. Accessed 9 September 2020.

F1. (2020). Formula 1 virtual grand prix series achieves record-breaking viewership. Available at: https://www.formulal.com/en/latest/article.formula-1virtual-grand-prix-series-achieves-record-breaking-viewership.7bv94UJPCtxW 0L5mwTxBHk.html. Accessed 9 October 2020.

Gainsbury, S. (2019). Gaming-gambling convergence: Research, regulation and reactions. Gaming Law Review, 23(2), 80-83.

Gainsbury, S., Russell, A., King, D., Delfabbro, P., \& Hing, N. (2016). Migration from social casino games to gambling: Motivations and characteristics of gamers who gamble. Computers in Human Behaviour, 63, 59-67.

Gambling Commission. (2016). Virtual currencies, eSports and social gaming - discussion paper. Birmingham: Gambling Commission. Available at: https://www.gamblingcommission.gov.uk/PDF/Virtual-currencieseSports-and-social-gaming-discussion-paper.pdf. Accessed 12 August 2020.

Gambling Commission. (2017a). Young people and gambling 2017. A research study among 11-16 year olds in Great Britain. Birmingham: Gambling Commission.

Gambling Commission. (2017b). Two men convicted after offering illegal gambling parasitic upon popular FIFA computer game. Birmingham: Gambling Commission. Available at: https://www.gamblingcommission. gov.uk/news-action-and-statistics/News/two-men-convicted-after-offeringillegal-gambling-parasitic-upon-popular-fifa-computer-game. Accessed 9 October 2020.

Gambling Commission. (2019). Young people and gambling 2019. A research study among 11-16 year olds in Great Britain. Birmingham: Gambling Commission.

Gambling Commission. (2020). Gambling business data on gambling during Covid-19 [Updated September 2020]. Birmingham: Gambling Commission. Available at https://www.gamblingcommission.gov.uk/news-action-and-sta tistics/Statistics-and-research/Covid-19-research/Covid-19-updated-Septem ber-2020/Gambling-business-data-on-gambling-during-Covid-19-updatedSeptember-2020.aspx. Accessed 9 October 2020.

Gambling Insider. (2012). Aristocrat purchases product madness. Gambling Insider. Available at: https://www.gamblinginsider.com/news/209/aristo crat-purchase-product-madness. Accessed 6 August 2020.

Georgen, C. (2015). Well played \& well watched: Dota 2, spectatorship, and eSports. Well Played a Journal on Video Games, Values, and Meaning, 4(1), 179-191. 
GGR Asia. (2020). Aristocrat digital to catch paused casino biz: Analysts. GGR Asia. Available at: https://www.ggrasia.com/aristocrat-digital-to-catchpaused-casino-biz-analysts/. Accessed 6 August 2020.

Goldgar, A. (2018). Tulip mania: The classic story of a Dutch financial bubble is mostly wrong. The Conversation. Available at: https://theconversation.com/ tulip-mania-the-classic-story-of-a-dutch-financial-bubble-is-mostly-wrong91413. Accessed 17 August 2020.

Graf, P. (2013). Are there risks posed by the convergence of social gaming and gambling? Speech to industry. Available at: http://www.gamblingcommiss ion.gov.uk/ghpress/news_archive/2013/are_there_risks_posed_by_the_c. aspx $+\& c d=6 \& h l=e n \& c t=c \operatorname{lnk} \& g l=u k$. Accessed 29 January 2014.

Greer, N., Rockloff, M., Browne, M., Hing, N., \& King, D. L. (2019). Esports Betting and Skin Gambling: A Brief History. Journal of Gambling Issues, 43.

Grove, C. (2016). Esports \& gambling: Where's the action. https://www.thelines. com/wpcontent/uploads/2018/03/Esports-and-Gambling.pdf.

Houghton, D., Nowlin, E., \& Walker, D. (2019). From fantasy to reality: The role of fantasy sports in sports betting and online gambling. Journal of Public Policy and Marketing. https://doi.org/10.1177/0743915619841365.

House of Commons. (2019). Digital, culture, media and sport committee oral evidence: Immersive and addictive technologies, HC 1846, Wednesday 19 June 2019. London: House of Commons.

House of Lords. (2020a). Select committee on the social and economic impact of the gambling industry corrected oral evidence: Social and economic impact of the gambling industry Tuesday $11^{\text {th }}$ February 2020. Available at: https://com mittees.parliament.uk/oralevidence/98/pdf/. Accessed 9 October 2020.

House of Lords. (2020b). Select committee on the social and economic impact of the gambling industry gambling harm-Time for action. London: House of Lords.

Hull, K., \& Lewis, N. P. (2014). Why twitter displaces broadcast sports media: A model. International Journal of Sport Communication, 7(1).

Johnson, M. (2019). Loot boxes and the gamblification of digital game design. Conference paper given at Alberta Gambling Research Institute Conference. Banff, Alberta

Kang, J. C. (2016). How the daily fantasy sports industry turns fans into suckers. New York Times Magazine. Available at: https://www.nytimes.com/ 2016/01/06/magazine/how-the-daily-fantasy-sports-industry-turns-fansinto-suckers.html?_r=0. Accessed 19 August 2020.

Kim, S. H., Wohl, M. J. A., Salmon, M. M., Gupta, R., \& Derevensky, J. (2015). Do social casino gamers migrate to online gambling? An assessment of migration rate and potential predictors. Journal of Gambling Studies, 31(4), 1819-1831. 
King, D. (2018). Online gaming and gambling in children and adolescents - Normalising gambling in cyber places. Victorian Responsible Gambling Foundation, Melbourne.

King, D., \& Delfabbro, P. (2018). Predatory monetization schemes in video games (e.g. loot boxes) and internet gaming disorder. Addiction, 113, 19671969.

King, D., Delfabbro, P., Gainsbury, S., Dreier, M., Greer, N., \& Billieaux, J. (2019). Unfair play? Video games as exploitative monetized services: An examination of game patents from a consumer protection perspective. Computers in Human Behaviour, 101, 131-143.

Larch, D. (2019). The history of the origins of esports. ISPO.com. Available at: https://www.ispo.com/en/markets/history-origin-esports\#: :text=On\%20O ctober $\% 2019 \% 2 \mathrm{C} \% 201972 \% 2 \mathrm{C} \% 20$ however,day $\% 20$ to $\% 20$ compete $\% 20 \mathrm{in} \%$ 20\%22Spacewar!. Accessed 23 August 2020.

McCarthy, C. (2019). PGS and Schalke04: The clubs imagining a future without football. Sports Business. Available at https://www.sportbusiness.com/2019/ 04/psg-and-schalke-04-the-football-clubs-imagining-a-future-without-foo tball/. Accessed 12 September 2020.

Miachon, N. (2018). Esports is the next biggest frontier in influencer marketing. Forbes. Available at: https://www.forbes.com/sites/forbescommunicationsc ouncil/2018/06/28/esports-is-the-next-biggest-frontier-in-influencer-mar keting/\#7690bdc06d7b. Accessed 12 September 2020.

Murphy, C. (2019). Flutter 'delighted' with US sports betting but counts the cost of future growth. SBC Americas. Available at: https://sbcamericas.com/ 2019/08/07/flutter-delighted-with-us-sports-betting-but-counts-the-costof-future-growth/. Accessed 15. August 2020.

National Council on Problem Gambling. (2019). National survey on gambling attitudes and experiences. Available at: https://www.ncpgsurvey. org/. Accessed 15 August 2020.

Nower, L., Caler, K., Pickering, D., \& Blaszczynski, A. (2018). Daily fantasy sports players: Gambling, addiction, and mental health problems. Journal of Gambling Studies, 34(3), 727-737. https://doi.org/10.1007/s10899-0189744-4.

Parke, J., Wardle, H., Rigbye, J., \& Parke, A. (2012). Exploring social gambling: Scoping classification and evidence review. Birmingham: Gambling Commission.

SBC Americas. (n.d.). Rush street interactive launches casino4fun at Gun Lake Casino. SBC Americas. Available at: https://sbcamericas.com/2019/07/ 25/rush-street-interactive-launches-casino4fun-at-gun-lake-casino/ Accessed 8 August 2020. 
Smith, J., Nairn, A., Rossi, R., Jones, E., \& Inskip, C. (2019). Biddable youth: Sports and esports Gambling Advertising on Twitter: Appeal to children, young \& vulnerable people. London: GambleAware.

US Court of Appeals for the $9^{\text {th }}$ Circuit. (2018). No. 16-35010. D.C. No.2:15-cv00612-MJP OPINION. Available at: http://cdn.ca9.uscourts.gov/datastore/ opinions/2018/03/28/16-35010.pdf. Accessed 10 August 2020.

Wardle, H., Moody, A., Spence, S., Orford, J., Volberg, R., Griffiths, M., Jotangia, D., Hussey, D., \& Dobbie, F. (2011). British gambling prevalence survey 2010. Birmingham: Gambling Commission.

Wardle, H. (2019). The same or different? Convergence of skin gambling and other gambling among children. Journal of Gambling Studies. https://doi. org/10.1007/s10899-019-09840-5.

Wardle, H., Petrovskaya, E., \& Zendle, D. (2020). Defining the esports bettor: Evidence from an online panel survey of emerging adults. International Gambling Studies. https://doi.org/10.1080/14459795.2020.1826559.

Wardle, H., \& Zendle, D. (2020). Loot boxes, gambling and problem gambling among young people: Results from a cross-sectional online survey. Cyberpsychology Behaviour and Social Networking, 24(4): 267-274.

Washington State Gambling Commission. (2018). Comment of Cheryl Kater. Available at: https://www.wsgc.wa.gov/sites/default/files/public/news / big-fish/Cheryl\%20Kater\%20Comment\%20In\%20Re\%20Big\%20Fish.pdf. Accessed 10 August 2020.

Yakimenko, S. (2019). Viewership results of The International 2019. Echarts.com. Available at: https://escharts.com/blog/results-the-internati onal-2019. Accessed 10 September 2020.

Zendle, D. (2020). Beyond loot boxes: A variety of gambling-like practices in video games are linked to both problem gambling and disordered gaming. PeerJ, 8, e9466. https://doi.org/10.7717/peerj.9466

Zendle, D., Meyer, R., Cairns, P., \& Ballou, N. (2020a). The prevalence of loot boxes in mobile and desktop games. Addiction. https://doi.org/10.1111/ add.14973.

Zendle, D., Meyer, R., \& Ballou, N. (2020b). The changing face of desktop video game monetisation: An exploration of exposure to loot boxes, pay to win, and cosmetic microtransactions in the most-played Steam games of 20102019. PLoS ONE. https://doi.org/10.1371/journal.pone.0232780. 
Open Access This chapter is licensed under the terms of the Creative Commons Attribution 4.0 International License (http://creativecommons.org/licenses/ by $/ 4.0 /$ ), which permits use, sharing, adaptation, distribution and reproduction in any medium or format, as long as you give appropriate credit to the original author(s) and the source, provide a link to the Creative Commons license and indicate if changes were made.

The images or other third party material in this chapter are included in the chapter's Creative Commons license, unless indicated otherwise in a credit line to the material. If material is not included in the chapter's Creative Commons license and your intended use is not permitted by statutory regulation or exceeds the permitted use, you will need to obtain permission directly from the copyright holder.

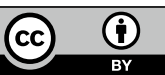

